MATEC Web of Conferences 9, 03001 (2013)

DOI: $10.1051 /$ matecconf/20130903001

(C) Owned by the authors, published by EDP Sciences, 2013

\title{
Effects of side walls on facade flame entrainment and flame height from opening in compartment fires
}

\author{
L.H. Hu ${ }^{1}$, K.H. Lu ${ }^{1}$, F. Tang ${ }^{1}$, M. Delichatsios ${ }^{2}$ and L.H. He ${ }^{1}$ \\ 1 State Key Laboratory of Fire Science, University of Science and Technology of China, \\ Hefei, Anhui 230026, China \\ 2 FireSERT, School of Built Environment and Built Environment Research Institute, University \\ of Ulster, Newtownabbey BT38 8GQ, Northern Ireland
}

\begin{abstract}
This paper presents an investigation of the side wall effects on facade flames ejected from the opening (such as a window) of an under-ventilated room fire. Experiments are carried out in a reduced-scale experimental setup, consisting of a cubic fire compartment having an opening with a vertical facade wall and two side walls normal to the façade wall. By changing the distance of the two side walls, the facade flame heights for different opening conditions (width, height) are recorded by a CCD camera. It is found that as the distance of the two side walls decreases the behavior the flame height can be distinguished into two regimes characterized by the dimensionless excess heat release rate, $\dot{Q}_{e x}^{*}$, outside the opening: (a) for the "wall fire" $\left(\dot{Q}_{e x}^{*} \leq 1.3\right)$, the flame height is shown to change little with decrease of side wall distance as the dominant entrainment is from the front direction (normal to the facade wall) independent of the side wall distances; (b) for the "axis-symmetrical fire" $\left(\dot{Q}_{e x}^{*}>1.3\right)$, the flame height increases significantly with a decrease in side wall distance as both the entrainment from the two side directions (parallel to the facade wall) and that from the front direction (normal to the facade wall) together apply. A global physically based non-dimensional factor $\mathrm{K}$ is then brought forward based on the side wall constraint effect on the facade flame entrainment to characterize the side wall effect on the flame height, by accounting for the dimensionless excess heat release rate, the characteristic length scales of the opening as well as the side wall separation distance. The experimental data for different opening dimensions and side wall distances collapse by using this global non-dimensional factor.
\end{abstract}

\section{INTRODUCTION}

For under-ventilated fully developed room fires in a building, there is a threat that flames can be ejected from the opening (such as a window), then induce fire spread to the upper floors leading to catastrophic loss of life and property. The facade flame height is a key parameter in fire spread to the adjacent upper floors, as a result of the radiation and convection of the flames on the facade. Many works [1-11] have been reported in the literatures on this parameter.

Recently, a model of facade flame heights has been brought up by Delichatsios et al [12-17]. The flames on the facade eject from the compartment opening when the heat release rate in the compartment is higher than the critical value $(1500 A \sqrt{H} \mathrm{~kW})$ with the mean facade flame height determined by the excess fuel burning outside the opening as well as by the opening geometry of the compartment. The mean flame height normalized by a characteristic opening length scale is given as a function of dimensionless excess heat release rate $\dot{Q}_{e x}^{*}$ :

$$
\frac{Z_{f}}{\ell_{1}}=f\left(\dot{Q}_{e x}^{*}\right)=f\left(\frac{\dot{Q}_{e x}}{\rho_{\infty} C_{p} T_{\infty} \sqrt{g} \ell_{1}^{5 / 2}}\right)
$$

This is an Open Access article distributed under the terms of the Creative Commons Attribution License 2.0, which permits unrestricted use, distribution, and reproduction in any medium, provided the original work is properly cited. 


\section{MATEC Web of Conferences}

$$
\ell_{1}=(A \sqrt{H})^{2 / 5}
$$

where $Z_{f}$ is the mean flame height (of $50 \%$ intermittency) above the neutral plane of the opening, $\rho_{\infty}$ is air density, $C_{p}$ is specific heat of air at constant pressure, $T_{\infty}$ is ambient temperature, $\mathrm{g}$ is acceleration of gravity, $\ell_{1}$ is the characteristic length scale representing the opening size ( $A$ and $H$ represent the area and height respectively). $\dot{Q}_{e x}$ is the excess heat release rate due to the burning of excess fuel outside the compartment defined as:

$$
\dot{Q}_{e x}=\dot{Q}-1500 A \sqrt{H} \mathrm{~kW} .
$$

It has been further proposed by Lee $[12,15]$ that the flame flowing outside the opening can be depicted as generated by a rectangular fire source having side dimensions $\ell_{1}$ and $\ell_{2}$ at the level of the neutral plane and providing a heat release rate of $\dot{Q}_{e x}$, where $\ell_{1}$ is defined by Eq. (2) and $\ell_{2}$ describes the competition of momentum to buoyancy flux at the opening, being a function of:

$$
\ell_{2}=\left(A H^{2}\right)^{1 / 4} \text {. }
$$

Furthermore, Lee [17] studied the facade flame behavior with a facing wall opposite to the opening of the compartment. When the separation distance between the facing wall and the facade wall decreases to be less than a characteristic length scale $\ell_{3}$ [17], it is found that the mean flame height is higher than that without facing wall because the opposite facing wall impedes the entrainment of fresh air into the flame.

There is another case that the facade flame is affected, namely, owing to side walls on either side of the opening. Such a restriction of side walls on enclosure facade fires mainly focusing on the effects of side walls on temperature distribution has been reported in [18]. Because the presence of side walls does not affect the critical heat release rate $(1500 A \sqrt{H}$, in $\mathrm{kW})$ [19-22], the main effect on the facade flame height is presumably due to the restriction of air entrainment from the two sides parallel to the facade wall. This effect of side walls on facade flame entrainment and thus the facade height behavior is investigated in detail in this work.

In this paper, a series of experiments are conducted in a reduced-scale cubic compartment of size $0.4 \mathrm{~m}$ having a vertical facade wall attached at the opening and two side walls symmetrically located at both sides of the opening. By changing the distance of the side walls, the flame heights for different opening dimensions are recorded using a CCD camera. A global non-dimensional factor $K$ is used to characterize the side wall effect, by including the dimensionless excess heat release rate, the characteristic length scales of the opening and the side wall separation distance. There are three sections following this introduction. The second section describes the experimental procedure, devices, equipment and conditions. The third section includes the results and discussion and finally, the section four summarizes the major findings.

\section{EXPERIMENTAL SETUP AND PROCEDURE}

\section{Experimental rig}

A reduced-scale model has been constructed to study the facade flame height outside a fire compartment under various side walls distances, as shown in Figure 1. The experimental model consists of a cubic fire compartment with a vertical facade wall $(2.2 \mathrm{~m}$ height and $1 \mathrm{~m}$ wide $)$ and two side walls $(2.1 \mathrm{~m}$ height and $0.6 \mathrm{~m}$ wide). The cubic fire compartment has dimensions $0.4 \mathrm{~m}$, with an inner lining of ceramic fiber boards ( $3 \mathrm{~mm}$ thickness) for thermal insulation. The opening is located in the center of the wall of the fire compartment. Five different geometries of openings are used in the experiments to represent different ventilation conditions. The specific opening geometries are also listed in Figure 1. Supported by steel structure and covered by a fire resisting board of $5 \mathrm{~mm}$ thickness, the facade wall is attached to the opening and the two side walls are positioned symmetrically at both sides of the opening. 

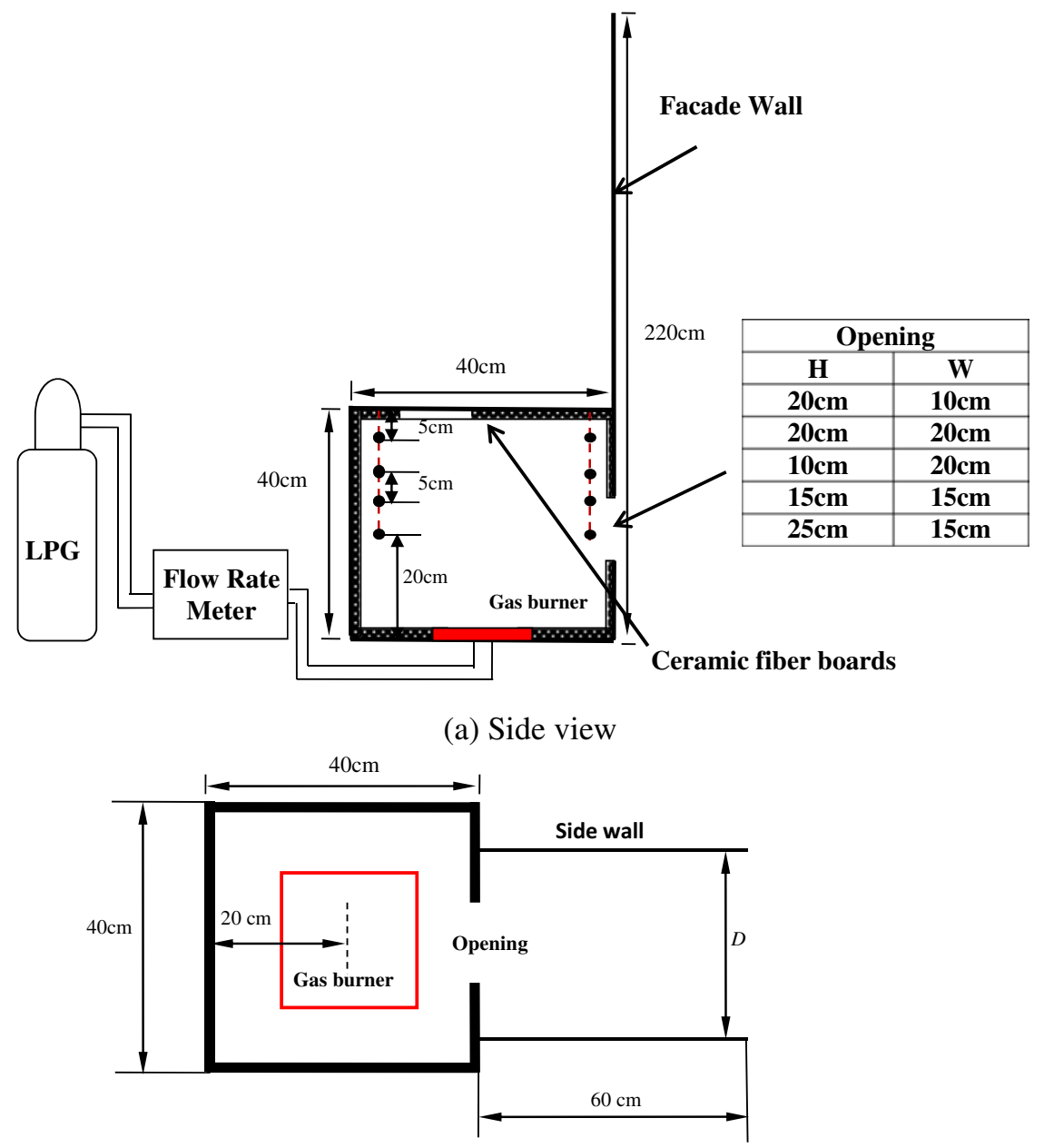

(b) Top view

Figure 1. Schematic of experimental setup.

\section{Measurement and experimental conditions}

In order to provide a steady fire source, Liquefied Petroleum Gas (LPG) is used as fuel and burnt in a steel-welded square porous gas burner of $0.2 \mathrm{~m}$, with small holes of diameter $0.5 \mathrm{~cm}$ drilled on the top surface at a spacing of $2 \mathrm{~cm}$. The gas burner is placed at the center of compartment floor with its top surface flush with the floor. The fuel supply rate into the fire compartment $\dot{V}_{f}$ is monitored and controlled by a gas flow meter of accuracy $0.1 \mathrm{~m}^{3} / \mathrm{h}$. All the experimental conditions are set to be under-ventilated and the total heat release rates calculated from the fuel supply rate according to the heat of combustion of the fuel are listed in the Table 1.

A total of $8 \mathrm{~K}$-type thermocouples of diameter $0.5 \mathrm{~mm}$ are divided in two trees located at the inner and outer corners of the enclosure respectively (see Fig. 1). The thermocouples in each thermocouple tree are $0.2 \mathrm{~m}, 0.25 \mathrm{~m}, 0.3 \mathrm{~m}$ and $0.35 \mathrm{~m}$ from the bottom of the enclosure. In each scenario when the combustion inside the enclosure reaches a steady state, the vertical temperature distribution is recorded. 
Table 1. Summary of experimental scenarios.

\begin{tabular}{|c|c|c|c|c|c|c|c|c|c|}
\hline \multirow{2}{*}{$\begin{array}{l}\text { Test } \\
\text { Series }\end{array}$} & \multicolumn{2}{|c|}{ Opening geometry } & \multirow{2}{*}{\multicolumn{4}{|c|}{ Separation Distance of side walls (m) }} & \multirow{2}{*}{\multicolumn{3}{|c|}{$\begin{array}{l}\text { Total heat release rate } \\
(\mathrm{kW})\end{array}$}} \\
\hline & Height $(\mathrm{m})$ & Width $(\mathrm{m})$ & & & & & & & \\
\hline 1 & 0.25 & 0.15 & 0.45 & 0.6 & 0.75 & No side walls & 39.9 & 44.3 & 48.8 \\
\hline 2 & 0.2 & 0.2 & 0.45 & 0.6 & 0.75 & No side walls & 39.9 & 44.3 & 48.8 \\
\hline 3 & 0.2 & 0.1 & 0.45 & 0.6 & 0.75 & No side walls & 39.9 & 44.3 & 48.8 \\
\hline 4 & 0.15 & 0.15 & 0.45 & 0.6 & 0.75 & No side walls & 39.9 & 44.3 & 48.8 \\
\hline 5 & 0.1 & 0.2 & 0.45 & 0.6 & 0.75 & No side walls & 39.9 & 44.3 & 48.8 \\
\hline
\end{tabular}
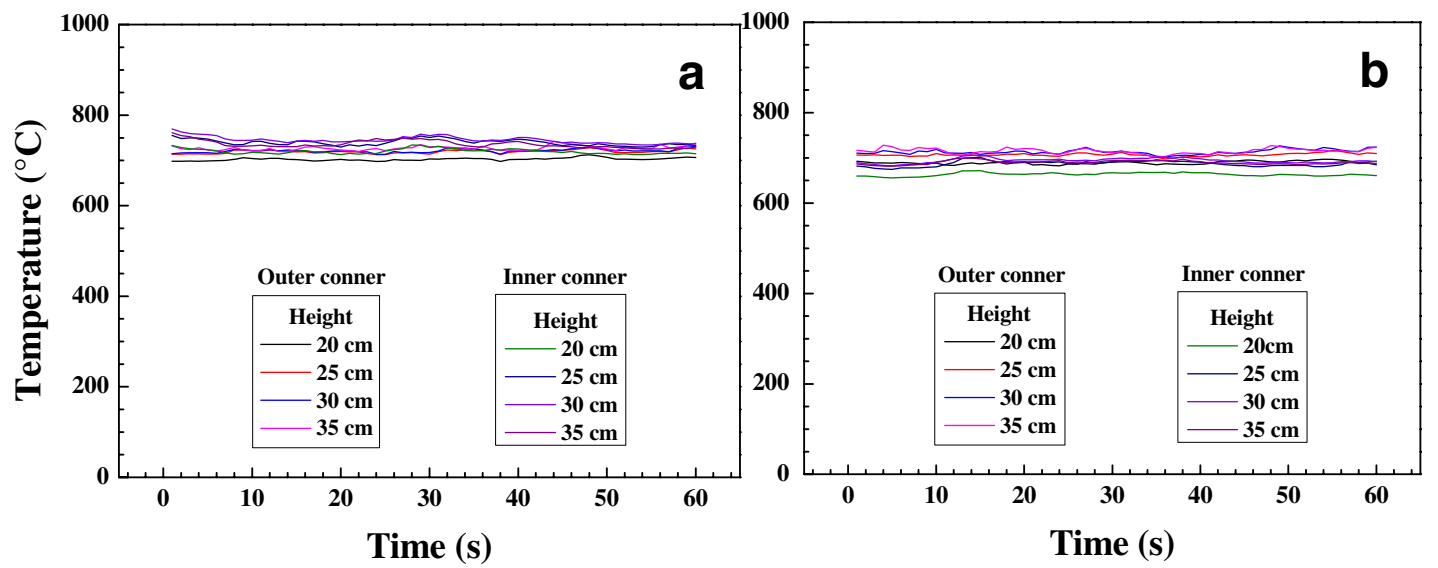

Figure 2. Typical temperature history measured showing to be steady and uniform inside the compartment for both with and without side wall. (a) opening $15 \mathrm{~cm} \times 15 \mathrm{~cm}$, HRR $44.3 \mathrm{~kW}$, no side wall and (b) opening $15 \mathrm{~cm} \times 15 \mathrm{~cm}$, HRR $44.3 \mathrm{~kW}$, side wall distance $60 \mathrm{~cm}$.

A CCD camera ( 25 frames per second, $720 \times 576$ pixels) captures the fluctuations of the ejected facade flames outside the fire compartment opening. The camera is fixed at $3 \mathrm{~m}$ away from the facade wall. The mean flame heights are obtained through image processing. The separations of the two side walls are $30 \mathrm{~cm}, 45 \mathrm{~cm}, 60 \mathrm{~cm}, 75 \mathrm{~cm}$ and $\infty$ ( $\infty$ also represents no side walls or open space). The experimental scenarios are summarized in Table 1 for the opening sizes, the separation distances of the two side walls, and the total heat release rates.

\section{RESULTS AND DISCUSSION}

\section{Mean flame height}

Figure 2 shows typical temperature history measured inside the enclosure for a certain opening $(0.15 \mathrm{~m} \times 0.15 \mathrm{~m})$ and heat release rate $(44.3 \mathrm{~kW})$ with no side walls and with a side wall separation distance of $60 \mathrm{~cm}$. It can be observed that the temperature remains steady and spatially uniform. The temperatures inside the enclosure for various openings are then obtained and shown to be independent of the separation of side walls, as evidenced in Figure 3 plotting normalized temperature rise [10] against side wall distances. Based on energy balance it can be shown from Figure 3, as done in [10], that the presence or the distance of side walls has no influence on the critical heat release rate $(1500 A \sqrt{H}$, in $\mathrm{kW}$ ) for under-ventilated conditions and a given opening geometry.

The mean flame height is obtained by the images recorded by the CCD camera in the experiments. A typical flame intermittency profile is displayed in Figure 4 after image processing [23]. The mean 


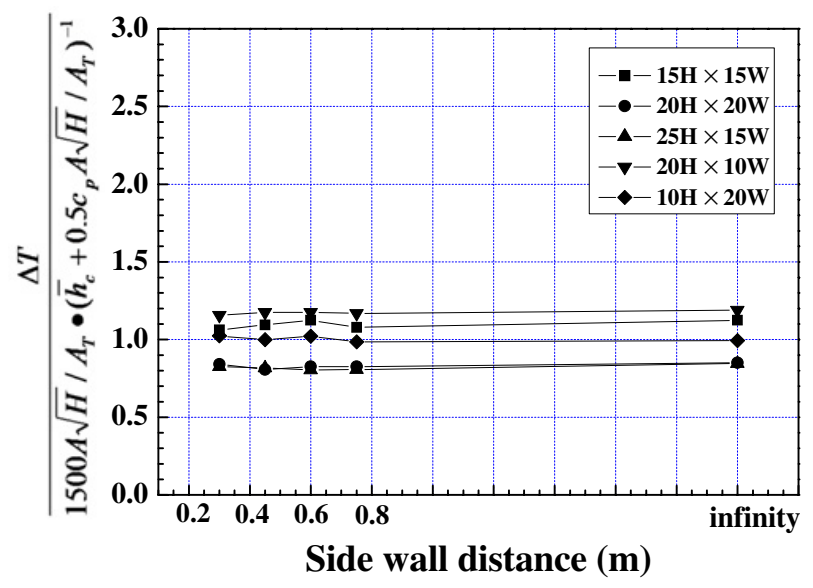

Figure 3. Non-dimensional temperature rise inside the compartment showing not change with side wall distances.

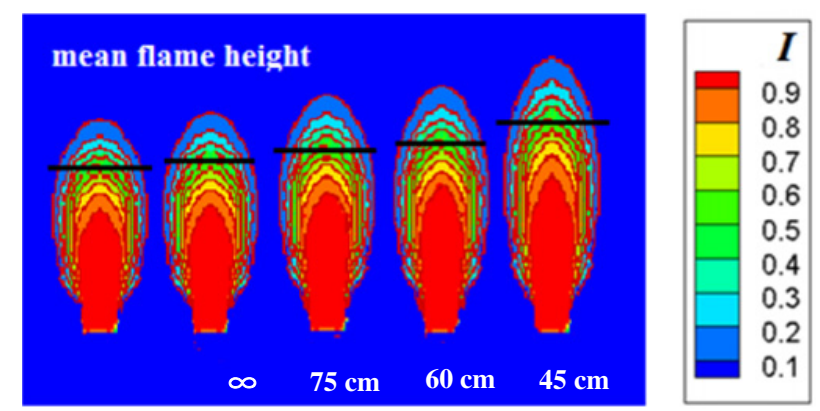

Figure 4. Flame intermittency and determination of mean flame height $(I=0.5)$ showing to increase with decrease in side wall distance for this opening $(15 \mathrm{~cm} \times 15 \mathrm{~cm})$.

flame height is obtained where the intermittency is 0.5 . Figure 5 shows the variation of mean flame height with side wall distances under different heat release rates and openings dimensions. It is found that the behavior of flame height with side wall distances can be distinguished into two regimes. The flame height is shown to increase with decrease in side wall distance for relative smaller openings (Figure 5a) of $10 \mathrm{~cm} \times 20 \mathrm{~cm}, 15 \mathrm{~cm} \times 15 \mathrm{~cm}$ and $20 \mathrm{~cm} \times 10 \mathrm{~cm}$; while being independent of the side wall distance for relative larger openings (Figure $5 \mathrm{~b}$ ) of $20 \mathrm{~cm} \times 20 \mathrm{~cm}$ and $25 \mathrm{~cm} \times 25 \mathrm{~cm}$. By a careful observation, it is found that for the relative smaller openings, the facade flame behaves like "a (half) axisymmetric fire" with relative larger thickness in the direction normal to the facade wall. In contrast, however, for relative larger openings, the facade flame behaves like "a wall fire" attaching to the facade wall with relative small thickness in the direction normal to the facade wall. The distinction of these two types of facade fire behaviors can be determined by a dimensionless excess heat release rate $\dot{Q}_{e x}^{*}$ ( $=\dot{Q}_{e x} / \rho_{\infty} C_{p} T_{\infty} \sqrt{g} \ell_{1}^{5 / 2}$ ) as normalized by the characteristic length scale $\ell_{1}$ of the opening (see also Eq. (1)). The critical value of $\dot{Q}_{e x}^{*}$ is reported to be about 1.3 [15]. The facade flame behaves like a "wall fire" when $\dot{Q}_{e x}^{*} \leq 1.3$, while like a "axisymmetric fire" when $\dot{Q}_{e x}^{*}>1.3$.

This indicates that the effect of side walls on the facade flame height should be considered by accounting for the constraint on flame entrainment. For "wall fire" condition where $\dot{Q}_{e x}^{*} \leq 1.3$, the entrainment is mainly from the front direction of the opening. The presence of the side walls has little influence as shown in Figure 5(a). On the contrary, when the flame behaves like "axisymmetric fire", $\left(\dot{Q}_{e x}^{*}>1.3\right)$, the effect of the side walls is significant as the entrainment from the two side directions 


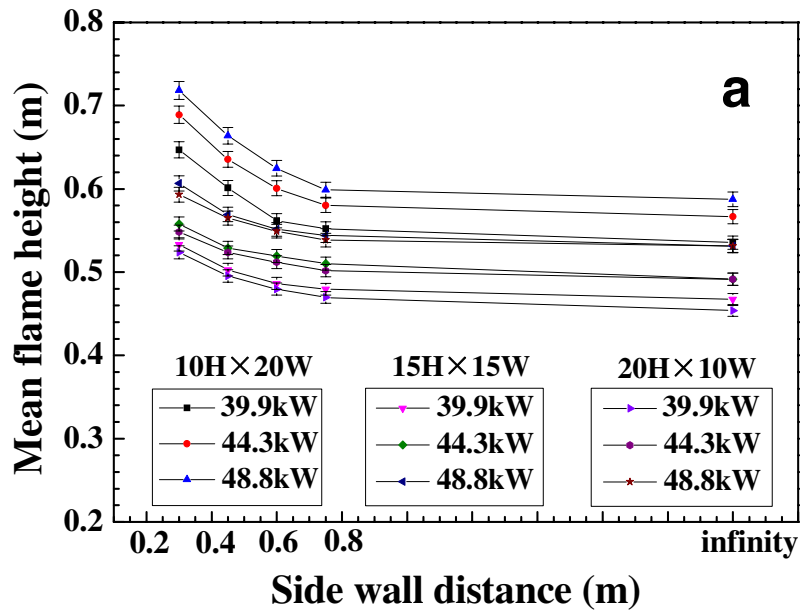

(a) for "axisymmetric fire like" behavior $\left(\dot{Q}_{e x}^{*}>1.3\right)$

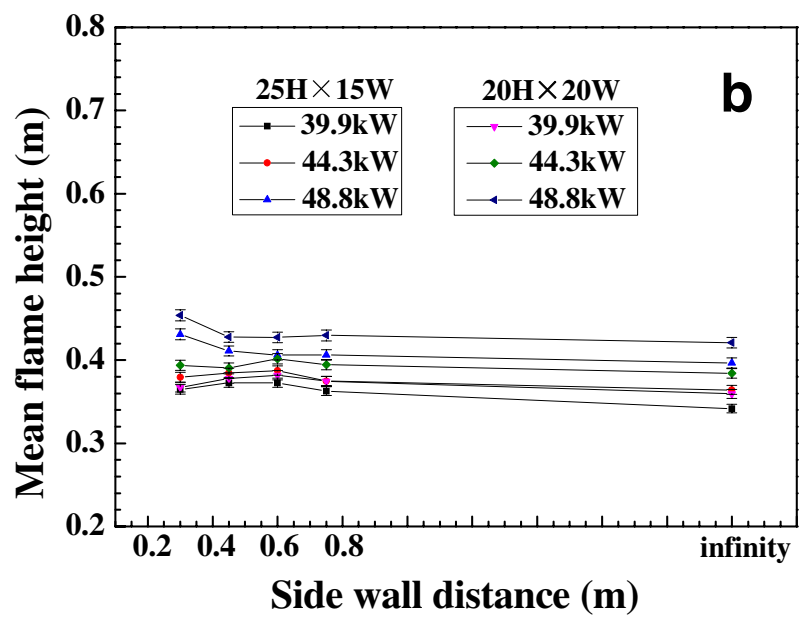

(b) for "wall fire like" behavior $\left(\dot{Q}_{e x}^{*}<1.3\right)$

Figure 5. Mean flame height versus side walls distances showing two different behavioral regimes, "axisymmetric fire" (flame height increases with decrease in side wall distance) and "wall fire" (flame height independent of side wall distance).

into the flame being considerable will be constrained in this case by the side walls. In the next section we propose a global non-dimensional parameter $K$ to characterize this effect on the facade flame height.

\section{The global non-dimensional factor $K$}

Firstly, we check the experimental data by using the normalized flame height and dimensionless excess heat release rate based on the characteristic length scale $\ell_{1}$, as shown in Figure 6 . It can be observed that when $\dot{Q}_{e x}^{*}>1.3$, the normalized values with side walls deviate from those with no side walls $(D=\infty)$. A global non-dimensional correction factor $K$ is then introduced to describe such effect on the change of the flame height:

$$
\frac{Z_{D}}{\ell_{1}}=K \frac{Z_{o}}{\ell_{1}}
$$




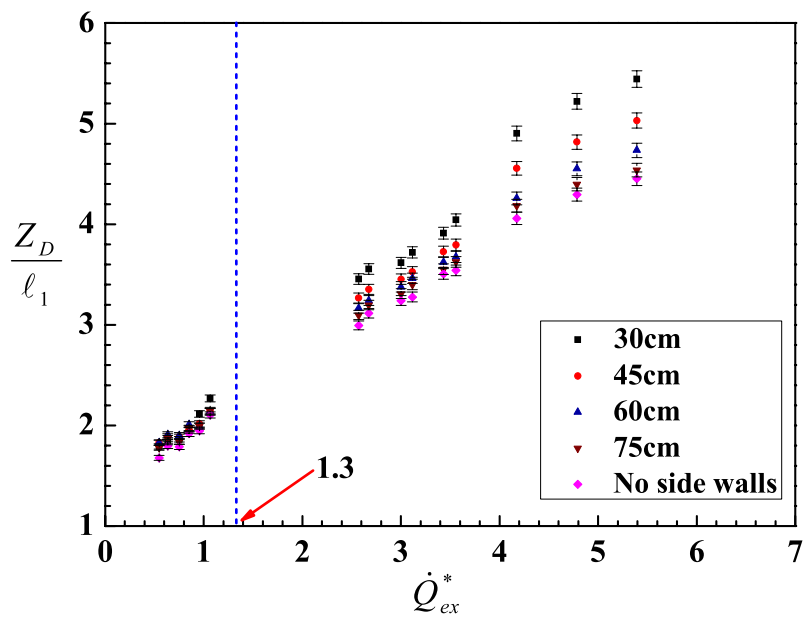

Figure 6. Experimental data of the normalized mean flame height and dimensionless excess heat release rate showing additional global correction factor needed to account for the effect of side wall distance on flame height change when $\dot{Q}_{e x}^{*}>1.3$.

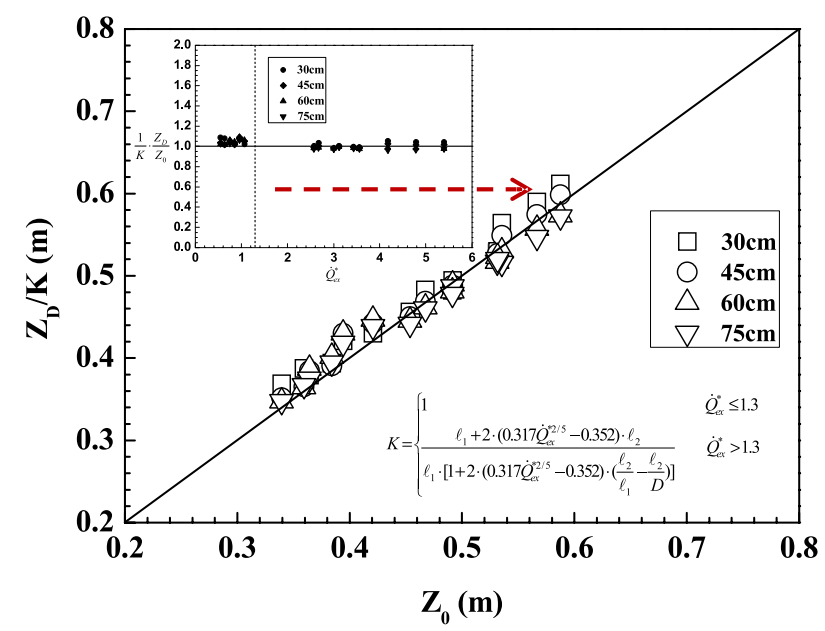

Figure 7. Normalized mean flame height corrected by the global non-dimensional factor K (Eq. (7)) showing it can well collapse the data for all side wall distances.

where $Z_{0}$ is the mean flame height without side walls and $Z_{D}$ is the mean flame height with side wall distance of $D$. In "wall fire" regime where $\dot{Q}_{e x}^{*} \leq 1.3$, the mean flame height is independent of the to the separation distance of the side walls and thus $K \approx 1$. Therefore, we mainly focus on the flame height change for "axisymmetric fire" regime where $\dot{Q}_{e x}^{*}>1.3$ in this section based on the concept shown in Figure 7.

According to the findings of Lee and Delichatsios $[12,15]$, the facade flame can be deemed to be produced by a rectangular fire source with two side dimensions of $\ell_{1}$ (parallel to the facade wall) and $\ell_{2}$ (normal to the to the facade wall) as shown in Figure 7a. Because the flame height is dominated by the entrainment from the three sides described by these two characteristic length scales, the global non-dimensional correction factor $K$ will be a function of the two characteristic length scales $\ell_{1}$ and $\ell_{2}$ as well as the normalized excess heat release rate (which determines the flame height when D 


\section{MATEC Web of Conferences}

is very large)

$$
K=f\left(D, \ell_{1}, \ell_{2}, \dot{Q}_{e x}^{*}\right)
$$

or in non-dimensional form

$$
K=f n\left(D / \ell_{1} \ell_{1} / \ell_{2}, \dot{Q}_{e x}^{*}\right) .
$$

A methodology is proposed next and implemented in the next section 3.3 on how to determine the functional relation in Eq. (8a). Regardless of the approximations in the theoretical approach the final functional relation as shown in Fig. 7 and expressed by Eq. (9) is valid.

All the experimental data are shown to be well collapsed in Figure 7. The mean flame height with side wall constrains with difference separation distances can be characterized by the following expressions:

$$
\begin{aligned}
& \frac{Z_{D}}{K}=Z_{0}=f\left(\dot{Q}_{e x}^{*}\right) \\
& K=f\left(D / \ell_{1}, \ell_{1} / \ell_{2}, \dot{Q}_{e x}^{*}\right)= \begin{cases}1 & \dot{Q}_{e x}^{*} \leq 1.3 \\
\frac{\ell_{1}+2 \cdot\left(0.317 \dot{Q}_{e x}^{* 2 / 5}-0.352\right) \cdot \ell_{2}}{\left[\begin{array}{l}
\ell_{1} \cdot\left[1+2 \cdot\left(0.317 \dot{Q}_{e x}^{* 2 / 5}-0.352\right)\right. \\
\left.\cdot\left(\frac{\ell_{2}}{\ell_{1}}-\frac{\ell_{2}}{D}\right)\right]
\end{array}\right.} & \dot{Q}_{e x}^{*}>1.3\end{cases}
\end{aligned}
$$

In addition for the second relation in Eq. (9b) the following condition is also satisfied:

$$
D>\ell_{1} .
$$

\section{CONCLUSIONS}

Experiments are carried out to investigate the side wall effect on the facade flame height from the opening of an under-ventilated compartment fire. A global non-dimensional parameter $K$ is determined based on the entrainment change owing the side walls as described by the two length scales $\ell_{1}$ and $\ell_{2}$. Major findings include:

(1) The effect of side wall on the facade flame height behaves in two different regimes. For small flames behaving like a "wall fire" $\left(\dot{Q}_{e x}^{*} \leq 1.3\right)$, the mean flame height is independent of the separation distance of side walls; but for relative larger flames behaving like a "axisymmetric fire" $\left(\dot{Q}_{e x}^{*}>1.3\right)$, the flame height increases with the decrease in side wall distance. It is physically explained by the fact that for the "wall fire like" facade flame, the entrainment is mainly from the front direction thus the side walls have little influence; while for the "axisymmetric fire like" one, both the entrainment from the two side directions and from the front direction have considerable contributions thus the side walls reduce the entrainment from the two side directions resulting in an increase in flame height.

(2) A global non-dimensional correction factor $K$, incorporating the separation distance of side walls, the two characteristic length scales of the opening as well as dimensionless excess heat release rate, is developed (Eq. (12)) to account for physically the entrainment change due to side wall constraint and hence the flame height increment. The experimental data for different opening dimensions and side wall separation distances collapse by this global non-dimensional factor (Fig. 7). 
This paper was supported by National Nature Foundation of China under Grant No.51176180, National Basic Research Program of China under Grant No. 2012CB719702, Fundamental Research Funds for the Central Universities, and Program for New Century Excellent Talents in University under Grant No. NCET-09-0914.

\section{References}

[1] S. Yokoi, Study on the Prevention of Fire Spread Caused by Hot Upward Current, Japan, Report 34, Report of the Building Research Institute, 1960.

[2] L.G. Seigel, The projection of flames from burning buildings, Fire Techno. 5 (1) (1969) 43-51.

[3] P.H. Thomas, M. Law, The projection of flames from buildings on fire, Fire Prevention Science and Technology 10 (1972) 19-26.

[4] X.Q. Sun, L.H. Hu, W.K. Chow, Y. Xu, F. Li, A theoretical model to predict plume rise in shaft generated by growing compartment fire, Inter. J. Heat Mass Trans. 54 (2011) 910-920.

[5] Oleszkiewicz, Heat Transfer from a Window Fire Plume to a Building Facade, HTD - Collected papers in Heat Transfer, vol. 123, Book No. H00526, 1989.

[6] K. Himoto, T. Tsuchihashi, Y. Tanaka, T. Tanaka, Modeling thermal behaviors of window flame ejected from a fire compartment, Fire Safety J. 44 (2009) 230-240.

[7] Y. Ohmiya, S. Yusa, J.I. Suzuki, K. Koshikawa, M.A. Delichatsios, Aerothermodynamics of fully involved enclosure fires having external flames, in: Fourth International Seminar Fire and Explosion Hazards, 2003, pp. 121-129.

[8] Y. Ohmiya, T. Tanaka, T. Wakamatsu, A room fire model for predicting fire spread by external flames, Fire Sci. Techno. 18 (1) (1998) 11-21.

[9] H. Huang, R. Oka, N. Liu, L. Zhang, Z. Deng, S. Kato, Experimental study of fire growth in a reduced-scale compartment under different approaching external wind conditions, Fire Safety J. 44 (2009) 311-321

[10] F. Tang, L.H. Hu, M.A. Delichatsios, K.H. Lu, W. Zhu, Experimental study on flame height and temperature profile of buoyant window spill plume from an under-ventilated compartment fire, Inter. J. Heat Mass Trans.55 (2012) 93-101.

[11] L.H. Hu, K.H. Lu, M. Delichatsios, L.H. He, F. Tang, An experimental investigation and statistical characterization of intermittent flame ejecting behavior of enclosure fires with an opening, Combust. Flame 159 (2012) 1178-1184.

[12] Y.P. Lee, M.A. Delichatsios, G.W.H. Silcock, Heat fluxes and flame heights in facades from fires in enclosures of varying geometry, Proc. Combust Inst. 31 (2) (2007) 2521-2528.

[13] M.A. Delichatsios, Y.P. Lee, P. Tofilo, A new correlation for gas temperature inside a burning enclosure, Fire Safety J. 44 (2009) 1003-1009.

[14] Y.P. Lee, M.A. Delichatsios, Y. Ohmiya, The study for the physics of the outflow from the opening of a burning enclosure, in: Proceedings of the 5th International Seminar on Fire and Explosion Hazards, 23-27 April 2007, Edinburgh, UK, pp. 381-392.

[15] Y.P. Lee, Heat Fluxes and Flame Heights in External Facade Fires, PhD thesis, FireSERT, University of Ulster, Belfast, United Kingdom, 2006.

[16] M. Coutin, J.M. Most, M.A. Delichatsios, M.M. Delichatsios, Flame heights in wall fires: effects of width, confinement and pyrolysis length, in: Proceedings of the 6th International Symposium on Fire Safety Science, 2000, pp. 729-740.

[17] Yee-Ping Lee, M.A. Delichatsios, Yoshifumi Ohmiya, Kaoru Wakatsuki, Akito Yanagisawa, Daisuke Goto, Heat fluxes on opposite building wall by flames emerging from an enclosure, Proc. Combust Inst. 31 (2) (2009) 2551-2558.

[18] J.I. Yamaguchi, T. Tanaka, Temperature profiles of window jet plume, Fire Sci. Techno. 24 (1) (2005) 17-38. 


\section{MATEC Web of Conferences}

[19] K. Himoto, T. Tsuchihashi, Y. Tanaka, T. Tanaka, Modeling the trajectory of window flames with regard to flow attachment to the adjacent wall, Fire Safety J. 44 (2009) 250-258.

[20] T. Nakao, A. Yanagisawa, A. Jo, K. Wakatsuki, Y. Ohmiya, Fire Plume Ejected from an Opening in Unconfined Space Part 1 Experimental Outline, Fire Sci. Techno. 26 (2007), No.4 Special Issue 497-503.

[21] Yanagisawa, A. Jo, T. Nakao, K. Wakatsuki, Y. Ohmiya, Fire Plume Ejected from an Opening in Unconfined Space Part 2 Generation Limit of the External Flame, Fire Sci. Techno. 26 (2007), No.4 Special Issue 505-510.

[22] Jo, T. Nakao, A. Yanagisawa, K. Wakatsuki and Y. Ohmiya, Fire Plume Ejected from an Opening in Unconfined Space Part 3 Behavior of Fire Plume Ejected from an Opening in the Vicinity of Opposed Walls, Fire Sci. Techno. 26 (2007), No.4 Special Issue 511-516.

[23] N. Otsu, A threshold selection method from gray-level histogram, IEEE Trans. Systems Man, and Cybernetics, 9 (1979) 62-66. 